\title{
Animales y Derecho en una sociedad global
}

\author{
Keywords: Derecho Animal; art. 13 TFUE; seres sintientes; Bienestar Animal
}

Los animales siempre han estado con nosotros. Desde los primeros albores de la Humanidad, la presencia de los animales es una constante, no sólo como dato fáctico, sino, principalmente, por su relación con los seres humanos. Una relación nunca rota, cambiante y definitivamente llena de interés.

La reflexión de pensadores y filósofos acerca de los animales y de la relación del hombre con los mismos data de muchos siglos atrás y las publicaciones sobre la materia constituyen una parte independiente y abundantísima de la bibliografía, p.e., sobre las ciencias de la Antigüedad (“Altertumswissenschaft”)[1].

Este dato por sí sólo, induce a reflexionar sobre la importancia que los animales han tenido en nuestras vidas y en el desarrollo de nuestra historia. Una historia que hemos tejido y enriquecido con nuestras aportaciones, las de los animales y las nuestras. Sin embargo, los animales, en dicha historia, no han jugado, tal vez, más que el papel de comparsas necesarios. Quizá no sea exagerado afirmar que la concepción instrumental que la sociedad tiene sobre los animales se ha plasmado en una visión imperturbablemente antropocéntrica de los acontecimientos, en la que los animales siempre han sido testigos sin voz, vehículo de relación con la divinidad, compañeros de batallas, refugio de caricias, medio de alimentación de diferentes tipos de culturas y concepciones sociales. Siempre presentes y siempre relegados, salvo en los últimos tiempos y, sobre todo en Occidente, donde el debate sobre su condición jurídica y sobre el uso que de ellos hacemos, nos ha inclinado a fijarnos en aspectos más profundos de su naturaleza y necesidades y a asumir algún compromiso más próximo a sus intereses, lo que, desde luego, se ha producido en épocas muy recientes. Me refiero al concepto de bienestar animal.

El Derecho, hasta hace relativamente poco tiempo, ha guardado sobre los animales una actitud de reserva cuando no de silencio absoluto. Durante siglos, todo lo que había que decir sobre la condición jurídica de los animales y sobre su papel en la vida social, se dijo hace ya muchos siglos. A partir de ahí, sólo ha habido esporádicas, aunque interesantes, incursiones en el mundo animal y debates auspiciados por las necesidades humanas, que siempre resultan mas apremiantes, que la reflexión sobre la inserción de los animales en la vida social y en el sistema jurídico.

En la historia del pensamiento, la filosofía griega destaca con luz propia en el debate sobre los animales. Durante siglos, ha sido una luminaria que ha inspirado desde biólogos y veterinarios, hasta a filósofos y pensadores de todas las tendencias. Algunas de sus principales ideas han servido como pauta para la reflexión y para el debate, cuando no como marco necesario para la exposición de las teorías relativas a la relación del hombre con el animal, sus diferencias y afinidades o la cuestión de la especie.

Una de los interrogantes que anima la discusión en el pensamiento filosófico griego es la de la capacidad de hablar[2] . En efecto, el habla constituye el elemento diferenciador, con base en el cual se establece la distinción entre humanos y animales. Sobre la base de dicha distinción, el otro parámetro diferencial entre humanos y animales es la capacidad de razonar, lo que conlleva la capacidad de pensarse o reconocerse a sí mismo, lo que -se afirma-, pertenece exclusivamente al ser humano.

Con tales premisas, el Derecho -que tiene su particular forma de regular las realidades-, ha hecho de la "persona" el núcleo central de atribución de obligaciones y de responsabilidades, partiendo de la concepción aristotélica de que el hombre racional y con capacidad de expresarse es el sujeto por eminencia del Derecho. El hilo conductor de tal concepción, que hace ondear el concepto de persona 
(unido al ser humano) como algo inamovible, impregna hasta la médula todo el pensamiento jurídico de Occidente.

Hoy en día, la relación de los Animales y el Derecho se ha ido estrechando. Las posiciones jurídicas sobre los animales están empezando a cambiar, aunque de fondo subsiste la categorización de los animales como "cosas" en propiedad y el rechazo a repensar -y quizá a ampliar- la aplicación del término "persona" a los propios animales. Pero, contra toda lógica asentada, así se ha hecho en la legislación de la India, donde se califica a los delfines como "personas no-humanas"[3] . No sé si el término es muy acertado o existe otro mejor, pero, para quien se extrañe de esta reflexión, quiero recordar que el término "persona", se aplica, desde hace muchos siglos, a entes que nada tienen que ver con un ser humano, y sí con patrimonios, actividades, funciones. Es decir, "personas jurídicas", no humanas...

El bienestar animal viene siendo objeto de una atención cada vez más amplia. Las preocupaciones de una sociedad como la nuestra parecen haber llegado a proyectarse también sobre cuestiones que, hace apenas unas décadas, le eran completamente ajenas. La sociedad demanda, cada día más, un mayor respeto por lo que, con cierta dosis de imprecisión, se suele conocer entre nosotros como “derechos de los animales”[4], o, más precisamente, "bienestar animal”[5]. Nuestra sociedad empieza a demandar no sólo que los animales domésticos reciban un trato digno y que no proliferen los abandonos y los maltratos, sino que los animales se beneficien de una consideración cada vez mayor, que reciban un trato adecuado a su condición de seres vivos sensibles y, aunque el debate aún no está generalizado en Europa, que la concepción misma del animal como objeto del Derecho alcance una mayor coherencia jurídica.

La división entre países de tradición católica y protestante (que, suele decirse, corresponde a los países del Centro-Norte o del Sur de Europa), se revela también como una división entre dos tradiciones enfrentadas de mayor o menor respeto por el bienestar animal. La propia UE, que nació como una Unión de base económica, reconoce no obstante en el articulado de su llamada Constitución, el rango de los animales como seres sintientes, que forman parte de nuestro entorno medioambiental. El Tratado de Lisboa, ha vuelto a insistir en la calificación de los animales como seres sensibles[6] , dejando abierta la puerta a un desarrollo legislativo que -se espera-, sea coherente con tal calificación[7]. Sin embargo, paradójicamente, las directivas europeas en tema de bienestar animal se aplican tendencialmente por los Ministerios de Agricultura, donde el animal suele contemplarse como un "producto”[8].

En Francia, desde los años 70 un buen grupo de intelectuales (entre los que tomó parte activa Marguerite Yourcenar, Miembro de l'Academie Française), promovió la celebración de numerosos Coloquios y Conferencias acerca de los derechos de los animales, hasta que la mejora de las condiciones de los animales traspasó las fronteras de la especulación teórica y se convirtió en una urgente tarea política, en la que dejó de hacerse referencia a la "protección del animal”[9] , para pasar a poner el acento en las relaciones hombre-animal y a considerar a los animales seres sensibles y a distinguirlos de las cosas inanimadas[10].

Por todo ello, en un contexto paradójico como es el de nuestra sociedad globalizada, deberían priorizarse, dentro de las legislaciones europeas algunos aspectos que hasta el presente sólo han sido objeto de una consideración teórica insuficiente. El binomio Animales y Derecho debería incluir:

- lograr una definición jurídica del animal, que lo aparte de la consideración de “cosa” o "producto”

- considerar el bienestar animal como un compromiso dentro del desarrollo sostenible

- proteger normativamente el sufrimiento innecesario de los animales (de granja o de experimentación)

- promover estudios sectoriales destinados a distintos ámbitos de interés: jurídico, social, económico, veterinario

- lograr aunar esfuerzos de los agentes potencialmente implicados en el bienestar animal:

- las administraciones públicas

- las sociedades protectoras,

- los agentes económicos encargados del transporte, la alimentación, el sacrificio o la experimentación científica y técnica, 
En definitiva, como ha puesto de relieve Tonio Borg, Comisario Europeo de Salud Animal y Consumo , el estudio, la educación, la formación profesional, es el instrumento necesario para avanzar en la mejora del trato que damos a los animales. Se lo debemos.

LA EDITORA

Teresa Giménez-Candela

Catedrática de Derecho Romano

Animal Law Profesor

Universitat Autònoma de Barcelona

Sígueme en Facebook: https://www.facebook.com/editora.da

[1] Una selección sumaria comprende las siguientes publicaciones: TOYNBEE, J.M.C., Animals in Roman Life and Art (Baltimore-London 1996), John Hopkins University Press (1st ed. en London 1973; Thames and Hudson); SAELIUS GILHUD, I., Animals, Gods and Humans (New York 2006); DIERAUER, U., Tier und Mensch in Denken der Antike. Studien zur Tierpsychologie, Anthropologie und Ethik (Amsterdam 1977); ALEXANDRIDIS, A./ WILD, M./ WINKLER-HORACEK, L., Mensch und Tier in Der Antike Grenzziehung und Grenzuberschreitung (Wiesbaden 2008).

[2] HEATH, J., The talking Greeks: speech, animals and the other in Homer, Aeschylus und Plato (2005); rev.:

[3] Giménez-Candela, Delfines: a propósito de una cuestión ética

[4] Francione, Introduction to Animal Rights: your child or the dog? (2000).

[5] Regan, The Case for Animal Rights (2004); Animal Rights and Human Obligations (1989); Cohen and Regan, The Animal Rights Debate (2001); Regan and Masson, Empty Cages: Facing the Challenge of Animal Rights (2005); Singer, Animal Liberation (New York 2002); In Defense of Animals: the second Wave (2006).

[6] Giménez-Candela, T., Seres Sintientes

[7] Tratado de Lisboa, 12.12.2007, part. B, Tit. II, Art 5b, n. 21: “...in formulating and implementing the Community’s agriculture, fisheries, transport, internal market, research and technological development and space policies, the Community and the Member States shall since animals are sentient beings, payfull regard to the welfare requirements of animals, while respecting legislative or administrative provisions and customs of the Member States relating in particular to religious rites, cultural traditions and regional heritage”.

[8] En este sentido, la Dirección General de Bienestar Animal, del Ministerio de Agricultura, Pesca y Alimentación;vid. (http://www.mapa.es/es/ganaderia/pags/bienestar/granja.htm http://www.mapa.es/es/ganaderia/pags/bienestar/laboratorio.htm), las secciones relativas a: "sector carne de porcino”, "sector aves de puesta”, “sector de carnes de aves”, “sectores de vacuno y ovino/caprino”, “sector apícola”, “sector cunícola”; pero también "emisiones de gases en ganadería”, "plan nacional de investigación de residuos”, o "normas zoosanitarias para la introducción de animales domésticos en España”.

[9] El Ministère d’Agriculture, impulsó la celebración en Paris de una reunión (23.10.1986), acerca de "Protection animale et société contemporaine” y en el 2002 la publicación de una “Charte des principes fondamentaux de la relation entre l'homme et l'animal”, bajo la premisa imperativa: "Respectons et protégeons les animaux”.

[10] Del 12 de septiembre 2007 al 20 de enero de 2008, pudo verse en Paris (Grand Halle de la Villette) la exposición “Bêtes et Hommes”, con el propósito de cuestionarse cómo los animales y el hombre se interrelacionan en el mundo actual, tomando como punto de vista la dimensión del animal en sí mismo, como un ser vivo en toda su amplitud. 